\title{
Ondansetron-droperidol combination vs. ondansetron or droperidol monotherapy in the prevention of postoperative nausea and vomiting
}

\author{
Paraskevi Matsota ${ }^{1}$, Maria Angelidi ${ }^{2}$, Aggeliki Pandazi ${ }^{1}$, Konstantinos N. Tzirogiannis ${ }^{2}$, \\ Georgios I. Panoutsopoulos ${ }^{3}$, Georgia Kostopanagiotou ${ }^{1}$
}

\begin{abstract}
${ }^{1} 2^{\text {nd }}$ Department of Anesthesiology, University Hospital "Attikon", Athens, Greece 2Department of Anesthesiology, "Tzanio" General Hospital, Athens, Greece ${ }^{3}$ Department of Nursing, University of Peloponnese, Orthias Artemidos and Plateon, Sparta, Greece
\end{abstract}

Submitted: 21 January 2013

Accepted: 12 April 2013

Arch Med Sci 2015; 11, 2: 362-370

DOI: $10.5114 /$ aoms.2015.50968

Copyright $\odot 2015$ Termedia \& Banach

\section{Abstract}

Introduction: Laparoscopic cholecystectomy is associated with a high incidence of postoperative nausea and vomiting. In this study we investigated comparatively the efficacy of combination therapy with ondansetron plus droperidol versus monotherapy with each agent alone in preventing postoperative nausea and vomiting following elective laparoscopic cholecystectomy. Material and methods: One hundred twenty-seven patients who underwent elective laparoscopic cholecystectomy under general anesthesia were included in the study, and assigned to one of the following three groups according to the antiemetic drug given intravenously at the end of the surgery: droperidol $1.25 \mathrm{mg}$ in group $\mathrm{D}$, ondansetron $4 \mathrm{mg}$ in group $\mathrm{O}$, and a combination of droperidol and ondansetron at the doses mentioned above in group $D+O$. Incidence of postoperative nausea and vomiting, and doses of given rescue antiemetics were recorded during the first postoperative day. The total drug cost per patient spent for postoperative nausea and vomiting management (including prophylactic antiemetics plus rescue postoperative antiemetics) was calculated.

Results: Combination therapy significantly reduced postoperative nausea and vomiting at $30 \mathrm{~min}, 3 \mathrm{~h}$ and $6 \mathrm{~h}$ after surgery compared with group $\mathrm{D}(p<0.01$ for all time points) and $O(p<0.01$ at $30 \mathrm{~min}, p<0.05$ at $3 \mathrm{~h})$ and required less rescue antiemetic treatment $(p<0.01)$. Total antiemetic cost analyses revealed no significant differences among the three groups $(p>0.05)$.

Conclusions: Pretreatment with ondansetron plus droperidol is more effective than monotherapy in preventing postoperative nausea and vomiting following laparoscopic cholecystectomy, without increasing the cost comparatively.

Key words: laparoscopic cholecystectomy, antiemetics, prophylaxis.

\section{Introduction}

Postoperative nausea and vomiting (PONV) is among the most common and unpleasant complications after general anesthesia and surgery [1]. Persistent or severe PONV can cause medical complications such as dehydration, electrolyte imbalance and delay in patient's discharge [2]. The overall incidence of PONV, a determinant of patient outcome and

\author{
Corresponding author: \\ Paraskevi Matsota \\ University Hospital \\ 1 Rimini St \\ Chaidari 12462, Greece \\ Phone: +30 2105015827, \\ +3069455544563 \\ E-mail: matsota@yahoo.gr
}


satisfaction, has been reported to vary from $10 \%$ to $79 \%$ [3]. The cause of PONV is multifactorial and depends on patient characteristics, factors related to anesthesia and surgery, and intensity of postoperative pain $[4,5]$. Antiemetic medications such as droperidol, promethazine, dexamethasone, metoclopramide and ondansetron have been studied for their efficacy in preventing PONV [6]. Failure of monotherapy with the above agents has been reported to be significant, and a combination of two antiemetic drugs, with different sites of action, has been suggested to provide better prophylaxis against PONV than a single antiemetic [7]. In addition, a drug combination, achieving a higher efficacy with less adverse effects, may be necessary, especially in patients at high risk for developing PONV [1].

Droperidol [8], a butyrophenone dopamine receptor antagonist, and ondansetron [9, 10], a selective 5-hydroxytryptamine type-3 (5-HT3) receptor antagonist, are two widely used antiemetics in anesthesia that exhibit some efficacy in the prevention of PONV [11-14]. Over the decades, droperidol has been proven to be a highly effective antiemetic, without side effects such as arrhythmias, sedation, extrapyramidal symptoms and dizziness, especially with doses higher than $1.25 \mathrm{mg}[8,15]$. The optimal adult dose of ondansetron for the prevention of PONV is considered to be $4 \mathrm{mg}$. The most common side effects of ondansetron are headache, flushing, dizziness and constipation [9].

Postoperative nausea and vomiting usually lasts for up to $24 \mathrm{~h}$ after anesthesia, and during this time patients are likely to experience nausea and episodes of emesis. Laparoscopic cholecystectomy is one of the commonest elective surgical procedures performed. Laparoscopic surgery under general anesthesia is also associated with a high incidence of PONV $[16,17]$.

In the present study, we investigated the hypothesis that a combination of droperidol with ondansetron is more effective than monotherapy with each agent alone in the prevention of PONV after elective laparoscopic cholecystectomy.

Our secondary aims were to evaluate the total cost of the antiemetic management, the safety profile of the administered prophylactic antiemetics and the patient's overall satisfaction regarding their prophylactic antiemetic treatment.

\section{Material and methods}

This prospective, randomized, double blinded study was approved by the Medical Ethics Committee of the "Attikon" University Hospital, Athens, Greece, and signed informed consent was obtained from all participants undergoing elective laparoscopic cholecystectomy between August
2007 and August 2010. Preoperative data collected included age, weight, American Society of Anesthesiologists' (ASA) physical status classification and smoking status. Exclusion criteria were: obesity class III (body mass index $\geq 40 \mathrm{~kg} / \mathrm{m}^{2}$ ), past medical history of motion sickness, diabetes mellitus, intake of opioids and antiemetics during the previous month, and episodes of emesis $24 \mathrm{~h}$ preoperatively. Participants were randomized with the closed envelope method to one of the following three study groups: group D: patients treated with a single dose of $1.25 \mathrm{mg}$ of droperidol given intravenously (iv) at the end of the surgery; group $\mathrm{O}$ : patients treated with a single dose of $4 \mathrm{mg}$ of ondansetron given iv at the end of the surgery; group $D+0$ : patients treated with a combination of droperidol and ondansetron given iv at the doses and time points mentioned above.

A standardized general anesthetic technique was used throughout the study. Patients were premedicated with intravenous ranitidine $(50 \mathrm{mg}$ ) and dimethindene maleate (4 mg). General anesthesia was induced by midazolam $(1.5 \mathrm{mg})$, fentanyl $(100 \mu \mathrm{g})$ and propofol $(2 \mathrm{mg} / \mathrm{kg})$. Rocuronium $(0.8 \mathrm{mg} / \mathrm{kg})$ was used to facilitate tracheal intubation. Anesthesia was maintained with continuous iv infusion of remifentanil (0.2-0.6 $\mu \mathrm{g} / \mathrm{kg} / \mathrm{min})$ and sevoflurane, while controlled ventilation was adjusted to maintain the end-tidal partial pressure of carbon dioxide at 35-45 mm Hg. After induction of anesthesia, a nasogastric tube was inserted in all patients and gastric contents were removed. The intraoperative monitoring included noninvasive arterial blood pressure (NIBP) measurement, heart rate $(H R)$, respiratory rate $(R R)$, oxygen saturation $\left(\mathrm{SpO}_{2}\right)$, end tidal carbon dioxide $\left(\mathrm{ETCO}_{2}\right)$ and end-tidal sevoflurane (ETsevo) concentration. Reversal of neuromuscular blockade was achieved with neostigmine $2.5 \mathrm{mg}$ and atropine $1 \mathrm{mg}$. The volume of the intraoperatively given fluids and the duration of both the operation and anesthesia were recorded.

Prevention of postoperative pain was achieved by intramuscular (im) administration of paracetamol $600 \mathrm{mg}$ and iv meperidine $(20 \mathrm{mg}$ ) given $10 \mathrm{~min}$ before the anticipated termination of surgery. Systematic administration of im paracetamol (600 mg qid) was also used as the main postoperative analgesic regimen. Supplementary pain relief was provided by administration of im meperidine $1 \mathrm{mg} / \mathrm{kg}$ if the pain score (tested by the Visual Analogue Scale (VAS 0-10)) was > 3. The intensity of postoperative pain and the opioid consumption were documented.

After the end of the operation, patients were monitored, according to the hospital protocol, for at least $1 \mathrm{~h}$ in the post-anesthesia care unit 
(PACU) and subsequently transferred to the ward. Electrocardiographic monitoring was applied to all patients for the whole study period for the tabulation of any drug-induced arrhythmias. Patients at the PACU and ward were attended and interviewed by a different team of investigators unaware of the study protocol. All patients were personally interviewed in the PACU at 30 and 60 min and in the ward at 3, 6, 12 and $24 \mathrm{~h}$, postoperatively. Data were collected with a structured questionnaire. Nausea was defined as a subjective, unpleasant sensation associated with awareness of the urge to vomit; vomiting was defined as the forceful expulsion of stomach contents from the mouth. Severity of nausea was assessed by response scores on a 0-10 verbal scale where 0 represented no nausea and 10 the worst nausea imaginable. Rescue antiemetic treatment (ondansetron $4 \mathrm{mg}$ iv) was given on demand if patients complained of nausea or vomiting and, per study protocol, if two or more vomiting episodes occurred within 30 min of each other. The occurrence of vomiting, the nausea scores and the need of a supplemental antiemetic were recorded.

The primary end-points of our study were the number of patients experiencing PONV, the percentage of patients with a complete response (no nausea and no vomiting) during the $24 \mathrm{~h}$ postoperative period, and the number of patients who required rescue antiemetic medication. Secondary outcomes included the cost analysis of the antiemetic management, the safety profile of the administered prophylactic antiemetic drugs, and the patient's overall satisfaction regarding PONV pretreatment. A cost analysis of the three groups was performed. The drug acquisition costs were provided by the hospital. The total drug cost per patient spent for the management of postoperative nausea and vomiting for each group (including the cost of the initial prophylactic antiemetic provided in each group plus the rescue postoperative antiemetic doses) was calculated. Moreover, to enrich our research we chose to compare the difference between total and initial cost. During the study period, any possible medication-related adverse effect including arrhythmias, headache, light-headedness, extrapyramidal side effects, flushing, lethargy, and sedation was documented. Sedation was assessed using the Ramsay Scale [18] with 6 grades of severity ( 1 = anxious, restless; 2 = oriented, tranquil; $3=$ responds to commands only; $4=$ brisk response to light glabellar tap or loud noise; $5=$ sluggish response to light glabellar tap or loud noise; $6=$ no response). The patient's overall satisfaction was assessed using a Yes/No response module. Satisfaction ratings were obtained $24 \mathrm{~h}$ after the end of the operation.

\section{Power of study for categorized postoperative nausea and vomiting}

For the study to have adequate power, sample size calculation was conducted a priori, using sample size estimation methods for ANOVA as described in the Norman \& Streiner Biostatistics book [19], and based on the following assumptions: 3 groups $(k=3)$, maximum dispersion of the distribution of means, and $d=\delta / S D$ (expected difference/standard deviation) $=0.8$. We assumed that $d=\delta / \mathrm{SD}=0.8$, thereby producing an estimated effect size $f>0.3$, because we considered a difference of 1 in PONV as a clinically meaningful difference and SD $=1.25$ as a reasonable value. Then, based on Table I (in the appendix of the Norman \& Streiner book) [20], we concluded that 36 patients per group would give the study adequate power when $a=0.05$ and $b=0.2$.

\section{0-30 min}

Although a convenient sample was included initially in the study, we increased the estimated sample size by $11 \%$ to at least 40 patients per group, to allow for possible erroneous assumptions and patient attrition, and post hoc power analysis concerning the null hypothesis of no differences among the group means, with the program G*Power (Buchner, Erdfelder, Faul \& Lang), based on: $\alpha=0.05$. Cohen's effect size $f=0.35$, which was calculated with the eta squared index $\left(\eta^{2}\right)$ [21] and sample size $n=127$, showed a power of 0.93 .

$$
1-3 \mathrm{~h}
$$

Cohen's effect size $f=0.32$, which was calculated with the eta squared index $\left(\eta^{2}\right)$ and sample size $n=127$, showed a power of 0.89 .

\section{Cost analysis}

The Shapiro-Wilk test was used to check normality of the variables. The Kruskal-Wallis test was applied in order to assess differences among groups for non-normally distributed variables (total cost, difference between total and initial cost). For paired comparisons the Mann-Whitney test was used, while adjustment of the type I error was done by the Bonferroni-Dunn method [22]. Results are presented as median (max-min).

\section{Statistical analysis}

Clinical and demographic results are presented as mean \pm SD for normally distributed variables and as number (\%) for categorical variables. The normality assumption of the measurements for each of the three groups was tested with the Shapiro-Wilk test (since the size of each group was 
Table I. Clinical and demographic data and factors associated with anesthesia and operation between study groups

\begin{tabular}{|c|c|c|c|}
\hline Parameter & Group D $(n=40)$ & Group O $(n=40)$ & Group D + O $(n=47)$ \\
\hline Number of patients & 40 & 40 & 47 \\
\hline Age [years] & $50.73 \pm 14.02$ & $53.8 \pm 16.07$ & $50.19 \pm 12.01$ \\
\hline \multicolumn{4}{|l|}{ Gender: } \\
\hline Female & $22(55)$ & $22(55)$ & $26(55.3)$ \\
\hline Male & $18(45)$ & $18(45)$ & $21(44.7)$ \\
\hline Weight [kg] & $75.63 \pm 11.58$ & $74.83 \pm 8.96$ & $76.13 \pm 8.01$ \\
\hline \multicolumn{4}{|l|}{ Smoking: } \\
\hline Yes & $20(50)$ & $19(47.5)$ & $24(51.1)$ \\
\hline No & $20(50)$ & $21(52.5)$ & $23(48.9)$ \\
\hline \multicolumn{4}{|l|}{ ASA: } \\
\hline I & $27(67.5)$ & $26(65)$ & $30(63.8)$ \\
\hline II & $13(32.5)$ & $14(35)$ & $17(36.2)$ \\
\hline Duration of operation [min] & $78 \pm 10.3$ & $78.75 \pm 10.6$ & $75.3 \pm 10.6$ \\
\hline Duration of anesthesia [min] & $93.38 \pm 11.16$ & $93.45 \pm 12.18$ & $92.02 \pm 11.81$ \\
\hline Intraoperative fluids [l] & $0.76 \pm 0.1$ & $0.73 \pm 0.1$ & $0.75 \pm 0.1$ \\
\hline
\end{tabular}

All values are expressed as mean $\pm S D$ except for gender, ASA status and smoking, where frequencies and relative frequencies are calculated. Data are presented as absolute number (n) and percentage (\%) of patients or mean \pm standard deviation. ASA - American Society of Anesthesiologists physical status classification

less than or equal to 50). The null hypothesis of the homogeneity of variances was tested with the Brown-Forsythe test [23] based on medians and was not rejected. Hence the Kruskal-Wallis test was conducted to evaluate differences in medians among the three groups.

Post hoc pairwise comparisons among the three groups were conducted with the Mann-Whitney $U$ statistic while the adjustment of the type I error was done by the Bonferroni-Dunn method [22].

Dichotomous variables were compared with the $\chi^{2}$ test since all expected cell frequencies were greater than or equal to five. All statistical analyses were performed using SPSS version 20.0. IBM SPSS for Windows v.20 software (IBM, New York, USA) was used for the analysis, and the statistical significance was set at $p<0.05$.

\section{Results}

A total of 150 patients, with an ASA physical status I or II, aged over 18 years, weighing less than $95 \mathrm{~kg}$, were initially enrolled in the study. In 10 cases a protocol deviation was recorded during their stay in the PACU (in 6 patients morphine was administered instead of meperidine and in 4 patients clonidine for the treatment of hypertension), in 8 individuals the operation was cancelled, and in 5 the procedure was converted to open cholecystectomy, and therefore all were excluded from the study; thus, 127 patients com- pleted the protocol and were finally included: 40 in group D, 40 in group $O$ and 47 in group D +0 . Groups were similar and no statistically significant differences were detected regarding age, gender, weight, smoking status, duration of operation, intraoperative fluid administration and intraoperative meperidine dose (Table I). No significant differences were also observed for the respiratory and hemodynamic variables $\left(\mathrm{SpO}_{2}, \mathrm{BP}, \mathrm{RR}, \mathrm{HR}\right)$ among groups (data not shown).

During the 24-hour study period, 35 patients experienced vomiting in group $D, 30$ in group 0 and 11 in group $D+O((D+O$ vs. $D, p<0.05)$, $(D+O$ vs. $O, p<0.05))$. Analysis also revealed that combination therapy was significantly more effective than monotherapy with both agents in preventing PONV at $30 \mathrm{~min}, 3 \mathrm{~h}$ and $6 \mathrm{~h}$ postoperatively (Table II). In relation to monotherapy, ondansetron was more effective in preventing PONV compared to droperidol only at $6 \mathrm{~h}$ postoperatively (Table II). The percentage of patients with a complete response (no nausea and no vomiting) during the 24-hour postoperative period was significantly greater in group D $+\mathrm{O}(38 \%)$ than in groups D $(3 \%, p<0.01)$ and $\mathrm{O}(5 \%, p<0.01)$.

Nausea scores were in general lower for group D $+O$ for all time points examined, with the exception of 60 min, compared with monotherapy groups, but this trend reached statistical significance only between group $\mathrm{O}$ and $\mathrm{D}+\mathrm{O}$ at $3 \mathrm{~h}(p<0.05)$ (Table II). 
Paraskevi Matsota, Maria Angelidi, Aggeliki Pandazi, Konstantinos N. Tzirogiannis, Georgios I. Panoutsopoulos, Georgia Kostopanagiotou

Table II. Number of patients (\%) with nausea or vomiting and nausea scores after laparoscopic cholecystectomy

\begin{tabular}{|c|c|c|c|}
\hline Time after surgery & Group D $(n=40)$ & Group O $(n=40)$ & Group D + O $(n=47)$ \\
\hline \multicolumn{4}{|l|}{ 0-30 min: } \\
\hline Nausea (\%) & $19(47.5)$ & $10(25)$ & $8(17)$ \\
\hline Vomiting (\%) & $11(27.5)$ & $8(20)$ & $0(0)$ \\
\hline Total PONV & $30(75)$ & $18(45)$ & $8(17)^{x+}$ \\
\hline Nausea score & $0.85 \pm 0.718$ & $0.72 \pm 1.170$ & $0.38 \pm 0.898$ \\
\hline \multicolumn{4}{|l|}{ 30-60 min: } \\
\hline Nausea (\%) & $5(12.5)$ & $7(17.5)$ & $16(34.0)$ \\
\hline Vomiting (\%) & $1(2.5)$ & $2(5)$ & $1(2.13)$ \\
\hline Total PONV & $6(15)$ & $9(22.5)$ & $17(36.2)$ \\
\hline Nausea score & $0.54 \pm 0.844$ & $1.03 \pm 1.44$ & $0.58 \pm 0.794$ \\
\hline \multicolumn{4}{|l|}{$1-3 \mathrm{~h}:$} \\
\hline Nausea (\%) & $18(45)$ & $18(45)$ & $20(42.5)$ \\
\hline Vomiting (\%) & $21(52.5)$ & $18(45)$ & $10(21.3)$ \\
\hline Total PONV & $39(97.5)$ & $36(90)$ & $30(63.8)^{\star \S}$ \\
\hline Nausea score & $1.37 \pm 0.761$ & $1.55 \pm 1.143$ & $0.780 \pm 0.917^{\neq}$ \\
\hline \multicolumn{4}{|l|}{$3-6 \mathrm{~h}:$} \\
\hline Nausea (\%) & $17(42.5)$ & $6(15)$ & $3(6.4)$ \\
\hline Vomiting (\%) & $2(5)$ & $2(5)$ & $0(0)$ \\
\hline Total PONV & $19(47.5)$ & $8(20)^{\ddagger}$ & $3(6.4)^{*}$ \\
\hline Nausea score & $0.45 \pm 0.504$ & $0.53 \pm 1.246$ & $0.170 \pm 0.670$ \\
\hline \multicolumn{4}{|l|}{$6-12 \mathrm{~h}:$} \\
\hline Nausea (\%) & $4(10)$ & $0(0)$ & $0(0)$ \\
\hline Vomiting (\%) & $0(0)$ & $0(0)$ & $0(0)$ \\
\hline Total PONV & $4(10)$ & $0(0)$ & $0(0)$ \\
\hline Nausea score & $1 \pm 0.2$ & 0 & 0 \\
\hline \multicolumn{4}{|l|}{$12-24 \mathrm{~h}:$} \\
\hline Nausea (\%) & $0(0)$ & $0(0)$ & $0(0)$ \\
\hline Vomiting (\%) & $0(0)$ & $0(0)$ & $0(0)$ \\
\hline Total PONV & $0(0)$ & $0(0)$ & $0(0)$ \\
\hline Nausea score & 0 & 0 & 0 \\
\hline
\end{tabular}

Subgroup analysis was conducted with the Kruskal-Wallis test using Bonferroni correction; $p<0.016$ was considered significant for pairwise comparisons between groups. Data presented as absolute number $(n)$ and percentage (\%) of patients for PONV and mean \pm standard deviation for nausea score; PONV - postoperative nausea and vomiting. Total PONV - total number of patients who experienced nausea or vomiting PONV, ${ }^{*} p<0.01 D+O$ vs. $D ; \dagger p<0.01 D+O$ vs. $0 ;{ }^{5} p<0.05 D+O$ vs. $0 ;{ }^{\ddagger} p<0.050$ vs. D; nausea score, ${ }^{\neq} p<0.05$ $D+O$ vs. $O$.

The number of patients who required rescue antiemetic treatment was statistically lower in group $\mathrm{D}+\mathrm{O}$ compared to the other groups (Table III). There were no statistically significant differences between groups $\mathrm{D}$ and $\mathrm{O}$ regarding the need for rescue antiemetic medication during the 24-hour observation period (Table III).
Regarding pain, group $\mathrm{D}+\mathrm{O}$ had significantly lower pain scores (VAS) compared to groups D $(p<0.01)$ and $\mathrm{O}(p<0.01)$ only at $30 \mathrm{~min}$. During the stay in the PACU, 24, 17 and 12 patients of groups $\mathrm{D}, \mathrm{O}$ and $\mathrm{D}+\mathrm{O}$ respectively were treated with rescue analgesic, and the analysis revealed significantly less consumption of meperidine in 
Table III. Number of patients who required rescue antiemetic medication (single dose of 4 mg ondansetron) in post-anesthetic care unit (PACU) and ward

\begin{tabular}{|lccc|}
\hline Time after surgery & Group D $(n=40)$ & Group O $(n=40)$ & Group D + O $(n=47)$ \\
\hline \begin{tabular}{l} 
PACU $(0-60 \mathrm{~min}):$ \\
\hline $\mathrm{mg}(\%)$
\end{tabular} & $19(47.5)$ & $25(62.5)$ & $43(91.5)^{*+}$ \\
\hline $4 \mathrm{mg}(\%)$ & $21(52.5)$ & $15(37.5)$ & $4(8.5)^{*+}$ \\
\hline Ward (1-24 h): & $17(42.5)$ & & $37(78.7)^{* \neq}$ \\
\hline $0 \mathrm{mg}(\%)$ & $23(57.5)$ & $20(50)$ & $10(21.3)^{* \neq}$ \\
\hline $4 \mathrm{mg}(\%)$ & & & \\
\hline
\end{tabular}

All pairwise comparisons between groups were conducted with $\chi^{2}$ test using Bonferroni correction. Data are presented as absolute number (n) and percentage (\%) of patients; PACU - post-anesthetic care unit. ${ }^{*} p<0.01 D+O$ vs. $D ;{ }^{\dagger} p<0.01 D+O$ vs. $0 ;{ }^{*} p<0.05 D+O$ vs. 0.

group $\mathrm{D}+\mathrm{O}$ compared to group $\mathrm{D}(p<0.01)$. No difference was observed for group $D$ vs. $O$ and group $\mathrm{O}$ vs. $\mathrm{D}+\mathrm{O}$ in the PACU. In the ward, no significant differences in opioid consumption were detected among groups for all time points examined.

The proportion of patients experiencing minor side effects during the 24-hour postoperative period including headache, dizziness and pruritus did not differ significantly among study groups. No statistically significant differences were observed between groups regarding sedation, and no major adverse effects attributed to droperidol, ondansetron, or their combination, were observed during the study. Specifically, 2 patients of group $\mathrm{O}$ and 1 patient of group $\mathrm{D}+\mathrm{O}$ reported having a mild headache, while in group D 1 patient reported lightheadedness and another 1 showed anxiety (Ramsay Scale grade 1).

Total cost analyses revealed no significant differences among the three groups (group D: $€ 9.21 \pm 4.14$, group 0 : $€ 8.62 \pm 3.32$, group $D+0$ : $€ 10.12 \pm 2.13, p>0.05)$. A statistically significant difference was observed between group $D+O$ vs. groups $D$ and $O$ (median, minimum-maximum range: $€ 0.0,0.0-4.6$ for group $D+O$ and $€ 4.6,0.0-$ 9.2 for groups $\mathrm{D}$ and $\mathrm{O}, p<0.01$ ) when differences between total and initial cost were calculated.

The number of patients who were satisfied with PONV management was higher in group D + O (96\%) compared with group D (85\%) and group $\mathrm{O}(90 \%)$. However, the above difference was not statistically significant $(p=0.230)$.

\section{Discussion}

According to the findings of the present study, combination therapy with droperidol and ondansetron is more effective in the prevention of PONV than monotherapy, with each agent providing higher response rates in patients undergoing laparoscopic cholecystectomy. Theoretically, the above observed effect should be attributed to the different receptors blocked by the two agents, a fact that provides combined and enhanced antiemetic activity in relation to monotherapy [13, 24, 25]. In agreement with our findings are the results of Pueyo et al. [24] and Wu et al. [26]. The above studies included only women, a high risk population for developing PONV, while our study included both men and women, and from this point of view our results not only further substantiate the superiority of combination therapy with ondansetron plus droperidol in the prevention of PONV but also expand its effect in the general population without a history of previous PONV.

In our study, individuals did not have factors associated with increased PONV according to their personal history, and also there were no differences in the distribution among groups regarding gender and smoking status.

Moreover, anesthetic and surgical factors associated with PONV were balanced among groups, so that the observed differences can be attributed to the different antiemetic drugs administered. All patients underwent laparoscopic cholecystectomy by the same team of anesthetists and surgeons. Duration of anesthesia and surgery as well as anesthetic drugs used (including intraoperative meperidine) were also similar in all groups.

So far, studies investigating comparatively the preventive antiemetic effect of ondansetron versus droperidol have yielded contradictory findings. Several studies $[11,27]$ have demonstrated ondansetron to be a superior prophylactic antiemetic to droperidol, while others have reported no difference $[28,29]$. In the present study, fewer patients experienced PONV in the ondansetron treated group compared with the droperidol treated group for all time intervals (with the exception of 30$60 \mathrm{~min}$ ) examined, but this difference was statistically significant only at $6 \mathrm{~h}$. Our findings could be attributed to the timing of antiemetic prophylaxis. In the aforementioned studies the drugs were administered at the induction of anesthesia. In our study both drugs and their combination were administered at the end of the surgery according to 
the recommended and optimal prophylactic doses and timing for administration of antiemetics in adults [30-32]. Another possible explanation is the fact that PONV has been evaluated after different kinds of surgery, mainly concerning gynecological operations. Recently, PONV following laparoscopic cholecystectomy was investigated in a systematic review and meta-analysis, which revealed the prophylactic antiemetic superiority of ondasentron, but this article included only studies comparing ondansetron with metoclopramide [33].

In our study, no significant difference was observed between monotherapy groups regarding the need for rescue antiemetic medication. However, both monotherapy groups required significantly more rescue antiemetic doses than the combined treatment group, increasing the cost of the postoperative emesis treatment. According to our cost analysis, the combination therapy of prophylactic antiemetics achieved greater effectiveness with similar drug cost compared with monotherapy. The superiority of the combined prophylactic antiemetic strategy versus monotherapies has also been documented even in studies where other antiemetics such as dexamethasone were examined [34, 35]. Pueyo et al. investigated the cost-effectiveness of the following three antiemetic combinations: droperidol-ondansetron, ondansetron-dexamethasone and droperidol-dexamethasone [36]. According to their results, the combination of droperidol plus ondansetron was found to be more cost-effective compared to the others. It is worth mentioning that in the above study, the administered doses of droperidol and ondansetron were the same as those used in our study.

Our study did not reveal any significant difference between the three groups regarding their safety profile. From the 127 participants of this study only 5 patients experienced minor side effects during the 24-hour postoperative period, including headache, dizziness and pruritus, while none presented major cardiac arrhythmias. Droperidol has a potential high incidence of undesirable side effects on cardiac rhythm when administered in doses higher than $1.25 \mathrm{mg}$. White et al. found that low prophylactic doses of droperidol ( $0.625 \mathrm{mg}$ and $1.25 \mathrm{mg}$ ) were not associated with a significant increase in the QT interval compared with placebo [37]. Moreover, another study showed no difference in the incidence of sedation, dizziness, and anxiety/agitation among patients receiving droperidol at doses equal to or less than $1.25 \mathrm{mg}$ compared to $4 \mathrm{mg}$ ondansetron or placebo [38], and this is in accordance with our findings.

Lower doses of droperidol $(0.625 \mathrm{mg})$ could be used in combination with ondansetron $4 \mathrm{mg}$. However, many studies have applied the combina- tion of $1.25 \mathrm{mg}$ droperidol with ondansetron $4 \mathrm{mg}$ $[35,36,39]$. The lower dose of $0.625 \mathrm{mg}$ of droperidol has also been used in a triple treatment therapy for PONV including ondansetron plus dexamethasone [39]. Taking also into account that $1.25 \mathrm{mg}$ has been associated with better cost-effectiveness compared with $0.625 \mathrm{mg}$ droperidol [40], we conducted the study using $1.25 \mathrm{mg}$ droperidol. Using a $1.25 \mathrm{mg}$ dose of droperidol, we observed neither increased sedation nor other major or minor medication-related side effects, a fact that also underlines, in addition to the droperidol-ondasentron combination's efficacy, its safety. Combination schemes including droperidol with smaller doses than $1.25 \mathrm{mg}$ such as $0.625 \mathrm{mg}$ could be evaluated in future studies.

The pain score was significantly lower in the combined therapy with ondansetron plus droperidol compared to monotherapy with each agent at $30 \mathrm{~min}$ after surgery. Moreover, postoperative meperidine consumption was lower in the $\mathrm{D}+\mathrm{O}$ group compared with the other groups in the first postoperative hour. This can probably be attributed to the fact that significantly fewer patients of the combination treatment group experienced abdominal pain and cramps due to vomiting.

In general, participants of our study were satisfied with their PONV pretreatment. Though no significant difference was observed between the three groups, a direct relationship was revealed between the efficacy of antiemetic therapy and the percentage of patients who were satisfied with their antiemetic management.

The incidence of PONV is high in patients undergoing abdominal laparoscopic surgery under general anesthesia [16, 17, 41], justifying the need of prophylactic treatment of PONV as a way to improve postoperative comfort and reduce complications. Taking also into account that droperidol and ondansetron have been shown to be superior to placebo in preventing PONV $[12,29]$, a placebo group was deemed unnecessary and for ethical reasons was not included, though its participation would have enhanced our findings. A potential limitation of our study is the fact that patients identified as high risk for PONV according to their medical history were excluded. Therefore further investigation is needed to confirm and expand our results in this population sample.

In conclusion, according to the findings of the present study, combination therapy with droperidol and ondansetron is more effective in preventing PONV following elective laparoscopic cholecystectomy than monotherapy with each agent alone, without increasing the cost or the major and minor medication-related side effects, a fact that makes it an effective and safe pretreatment strategy. 


\section{Acknowledgments}

P. Matsota and M. Angelidi contributed equally to the study design and motivated the study.

\section{Conflict of interest}

The authors declare no conflict of interest.

\section{References}

1. Golembiewski J, Chernin E, Chopra T. Prevention and treatment of postoperative nausea and vomiting. Am J Health Syst Pharm 2005; 62: 1247-60.

2. Muchatuta NA, Paech MJ. Management of postoperative nausea and vomiting: focus on palonosetron. Ther Clin Risk Manag 2009; 5: 21-34.

3. Apfel CC, Laara E, Koivuranta M, Greim CA, Roewer N. A simplified risk score for predicting postoperative nausea and vomiting: conclusions from crossvalidations between two centers. Anesthesiology 1999; 91: 693-700.

4. Ku CM, Ong BC. Postoperative nausea and vomiting: a review of current literature. Singapore Med J 2003; 44: 366-74.

5. Chatterjee S, Rudra A, Sengupta S. Current concepts in the management of postoperative nausea and vomiting. Anesthesiol Res Pract 2011; 2011: 748031.

6. Golembiewski JA, O'Brien D. A systematic approach to the management of postoperative nausea and vomiting. J Perianesth Nurs 2002; 17: 364-76.

7. Kranke P, Eberhart LH. Possibilities and limitations in the pharmacological management of postoperative nausea and vomiting. Eur J Anaesthesiol 2011; 28: 758-65.

8. Henzi I, Sonderegger J, Tramer MR. Efficacy, dose-response, and adverse effects of droperidol for prevention of postoperative nausea and vomiting. Can J Anesth 2000; 47: 537-51.

9. Tramer MR, Reynolds DJ, Moore RA, McQuay HJ. Efficacy, dose-response, and safety of ondansetron in prevention of postoperative nausea and vomiting. Anesthesiology 1997; 87: 1277-89.

10. Kovac A, McKenzie R, O'Connor T, et al. Prophylactic intravenous ondansetron in female outpatients undergoing gynaecological surgery: a multicentre dose-comparison study. Eur J Anaesthesiol 1992; 6: 37-47.

11. Swiatkowski J, Goral A, Dzieciuch JA, Przesmycki K. Assessment of ondansetron and droperidol for the prevention of post-operative nausea and vomiting after cholecystectomy and minor gynaecological surgery performed by laparoscopy. Eur J Anaesthesiol 1999; 16: 766-72.

12. Fortney JT, Gan TJ, Graczyk S, et al. A comparison of the efficacy, safety, and patient satisfaction of ondansetron versus droperidol as antiemetics for elective outpatient surgical procedures. Anesth Analg 1998; 86: 731-8.

13. Williams OA, Clarke FL, Harris RW, Smith P, Peacock JE. Addition of droperidol to patient-controlled analgesia: effect on nausea and vomiting. Anaesthesia 1993; 48: 881-4.

14. Pearman MH. Single dose intravenous ondansetron in the prevention of postoperative nausea and vomiting. Anaesthesia 1994; 49: S11-5.

15. Melnick B, Sawyer R, Karambelkar D, Phitayakorn P, Uy NT, Patel R. Delayed side effects of droperidol after ambulatory general anesthesia. Anesth Analg 1989; 69: 748-51.

16. Sung YF, Wetchler BV, Duncalf D, Joslyn AF. A double-blind, placebo-controlled pilot study examining the effectiveness of intravenous ondansetron in the prevention of postoperative nausea and emesis. J Clin Anesth 1993; 5: 22-9.

17. Watcha MF, White PF. Postoperative nausea and vomiting. Its etiology, treatment and prevention. Anesthesiology 1992; 77: 162-84.

18. Ramsay MA, Savege TM, Simpson BR, Goodwin R. Controlled sedation with alphaxalone-alphadolone. Br Med J 1974; 2: 656-9.

19. Norman G, Streiner D. More than two groups. In: Biostatistics the bare essentails. Decker 1998; 70-1.

20. Norman G, Streiner D. Biostatistics the bare essentails. Decker 1998; 250.

21. Sheskin D. Handbook of parametric and nonparametric statistical procedures. 3rd ed. Chapman \& Hall/CRC 2004; 729-30.

22. Sheskin D. Handbook of parametric and nonparametric statistical procedures. 3rd ed., Chapman \& Hall/CRC 2004; 774-8.

23. Brown M, Forsythe A. Robust tests for the equality of variances. J Am Statist Assoc 1974; 69: 364-7.

24. Pueyo FJ, Carrascosa F, Lopez L, Iribarren MJ, García-Pedrajas F, Saez A. Combination of ondansetron and droperidol in the prophylaxis of postoperative nausea and vomiting. Anesth Analg 1996; 83: 117-22.

25. Helmers JH, Briggs L, Abrahamsson J, et al. A single iv dose of ondansetron $8 \mathrm{mg}$ prior to induction of anaesthesia reduces postoperative nausea and vomiting in gynaecological patients. Can J Anaesth 1993; 40: 1155-61.

26. Wu O, Belo SE, Koutsoukos G. Additive anti-emetic efficacy of prophylactic ondansetron with droperidol in out-patient gynecological laparoscopy. Can J Anaesth 2000; 47: 529-36.

27. Paxton LD, McKay AC, Mirakhur RK. Prevention of nausea and vomiting after day case gynaecological laparoscopy. A comparison of ondansetron, droperidol, metoclopramide and placebo. Anaesthesia 1995; 50: 403-6.

28. Tang J, Watcha MF, White PF. A comparison of costs and efficacy of ondansetron and droperidol as prophylactic antiemetic therapy for elective outpatient gynecologic procedures. Anesth Analg 1996; 83: 304-13.

29. Desilva PH, Darvish AH, McDonald SM, Cronin MK, Clark K. The efficacy of prophylactic ondansetron, droperidol, perphenazine, and metoclopramide in the prevention of nausea and vomiting after major gynecologic surgery. Anesth Analg 1995; 81: 139-43.

30. Gan TJ, Meyer TA, Apfel CC, et al. Society for Ambulatory Anesthesia guidelines for the management of postoperative nausea and vomiting. Anesth Analg 2007; 105 : 1615-28.

31. Gan TJ, Meyer T, Apfel CC, et al. Consensus guidelines for managing postoperative nausea and vomiting. Anesth Analg 2003; 97: 62-71.

32. McCracken G, Houston P, Lefebvre G; Society of Obstetricians and Gynecologists of Canada. Guideline for the management of postoperative nausea and vomiting. J Obstet Gynaecol Can 2008; 30: 600-7.

33. Wu SJ, Xiong XZ, Cheng TY, Lin YX, Cheng NS. Efficacy of ondansetron vs. metoclopramide in prophylaxis of postoperative nausea and vomiting after laparoscopic cholecystectomy: a systematic review and meta-analysis. Hepatogastroenterology 2012; 59 2064-74.

34. Wang PK, Tsay PJ, Huang CC, et al. Comparison of dexamethasone with ondansetron or haloperidol for prevention of patient-controlled analgesia-related postoperative nausea and vomiting: a randomized clinical trial. World J Surg 2012; 36: 775-81. 
35. Kranke P, Eberhart LH. Postoperative nausea and vomiting: rational algorithms for prevention and treatment based on current evidence. Anasthesiol Intensivmed Notfallmed Schmerzther 2009; 44: 286-94.

36. Pueyo FJ, López-Olaondo L, Sanchez-Ledesma MJ, Ortega A, Carrascosa F. Cost-effectiveness of three combinations of antiemetics in the prevention of postoperative nausea and vomiting. Br J Anaesth 2003; 91: 589-92.

37. White PF, Song D, Abrao J, Klein KW, Navarette B. Effect of low-dose droperidol on the QT interval during and after general anesthesia: a placebo-controlled study. Anesthesiology 2005; 102: 1101-5.

38. Domino KB, Anderson EA, Polissar NL, et al. Comparative efficacy and safety of ondansetron, droperidol, and metoclopramide for preventing postoperative nausea and vomiting: a meta-analysis. Anesth Analg 1999; 88: 1370-9.

39. Schnaider TB, Vieira AM, Brandão AC. Comparative study of anti-emetics and their association, in the prevention of postoperative nausea and vomiting in patients undergoing gynecologic surgeries. Rev Bras Anestesiol 2008; 58: 614-22.

40. Hill RP, Lubarsky DA, Phillips-Bute B, et al. Cost-effectiveness of prophylactic antiemetic therapy with ondansetron, droperidol, or placebo. Anesthesiology 2000; 92 958-67.

41. Wang JJ, Ho ST, Liu YH, et al. Dexamethasone reduces nausea and vomiting after laparoscopic cholecystectomy. Br J Anaesth 1999; 83: 772-5. 